\title{
Optimization of Crude Oil Trade Structure: A Complex Network Analysis
}

\author{
Gaogao Dong $\mathbb{D}^{1},{ }^{1}$ Ting Qing, ${ }^{1}$ Lixin Tian, ${ }^{1,2}$ Ruijin Du $\mathbb{D}^{1},{ }^{1}$ and Jingjing Li $^{1}$ \\ ${ }^{1}$ Center of Energy Development and Environmental Protection, School of Mathematical Sciences, Jiangsu University, \\ Zhenjiang 212013, Jiangsu, China \\ ${ }^{2}$ School of Mathematical Science, Nanjing Normal University, Nanjing 210042, Jiangsu, China
}

Correspondence should be addressed to Ruijin Du; dudo999@126.com

Received 3 June 2020; Accepted 16 December 2020; Published 4 January 2021

Academic Editor: Dimitri Volchenkov

Copyright ( 2021 Gaogao Dong et al. This is an open access article distributed under the Creative Commons Attribution License, which permits unrestricted use, distribution, and reproduction in any medium, provided the original work is properly cited.

With the contradiction between supply and demand being intensified, the unreasonable crude oil trade structure has become increasingly prominent. Therefore, optimizing the supply and demand structure of the global crude oil trade is an urgent problem, which has become one of the crucial factors affecting the energy strategy and economic development of each country. This paper builds an optimization model that aims at minimizing crude oil trade costs based on the complex network theory. Meanwhile, an optimal solution generation approach is proposed and developed in this paper. Compared with the preoptimized trade network, the proposed model can effectively reduce the trade cost. By topological analysis of the trade network and its optimal configuration, we obtain that both the preoptimized and optimized crude oil trade networks follow power-law distribution. By using the minimum spanning tree, we find that the major crude oil net exporting countries have the most significant influence and are at the core in the optimized trade structure. This work focuses on the sustainable development of the global crude oil trade and provides a fresh perspective for the optimal crude oil trade system. Moreover, the methodology and model may be applied in the investigation of optimization for other energy system structures.

\section{Introduction}

Currently, as the primary energy source in the world, crude oil is strategically vital to all countries on the earth. The factor endowment and the difference between supply and demand of crude oil resources are critical driving forces for the development of international crude oil trade. Recently, in order to reveal the interaction between the trade countries of the crude oil trading system from the strategic scope, a growing number of scholars and researchers have studied global crude oil trade from the perspective of complex network theory. The basic view is of the research of complex network where the nodes are the countries, and the edges are the trade relationship as a complex network. The relationship between nodes in the trading system in the form of a network is explained. In the past ten years, complex network has become an essential tool for studying complex systems and has been applied in more and more fields [1-8].
Complex network method can analyze the world-wide trade system entirely and partly so as to reveal many new features of the crude oil trade topologically and dynamically. Some studies are related to the characteristics and evolution of international crude oil trade relations [9-11]. Yang et al. [9] examined the geography of global crude oil flows and its evolution based on complex network. Xi et al. [10] studied the impact of crude oil trade pattern changes of the Belt and Road countries on each country's GDP based on the complex network and econometric theory. Zhang et al. [11] applied social network to investigate structure characteristics and evolution pattern with petroleum trade data of countries along the Belt and Road Initiative. Some studies are related to trade roles and preferences of cooperation partners [12-14]. In Ref. [12], the authors explored whether the countries' local trade pattern can reflect their preferences of selecting trade partners in different commodity's markets. Du et al. [13] applied the top 1 network model to reflect 
countries' preference in choosing oil trade partners. Zhong et al. [14] showed that a better understanding of the roles of trading countries in the international fossil fuel trade is crucial for trade security and policy optimization. Some studies are related to stability and security of crude oil trade network [15-20]. The authors of Ji et al. [15] constructed a global oil trade core network to analyze the overall features, regional characteristics, and stability of the oil trade using complex network theory. Sun et al. [16] constructed weighted and unweighted international oil trade networks based on complex network theory to analyze the stability of the international oil trade network from short-term and long-term aspects. An et al. [17] built a trading-based network model of international crude oil to study the evolution of scales, stability, hierarchy structure, and partition over time. Guan et al. [18] introduced the link prediction approach to assessing potential trade links. There also exist some studies about the systemic risk in crude oil trade by studying the interaction patterns among the global crude oil import dependency countries $[19,20]$.

Previous researches provide important insights into global crude oil trade, but these works often consider the actual crude oil trade system. Few studies have researched the optimization of crude oil supply and demand structure. Practically, influenced by factors such as long-distance transportation, geographical distribution, and political agreement of crude oil trade, there are poorly functioning supply and demand structures in the actual crude oil trading system. For example, strong dependence on specific countries and routes leads to high trade costs and waste of resources. Based on the existing achievements, this paper focuses on the structural optimization of the global crude oil trading system.

In this way, the structural optimization of the crude oil trade should gain particular attention. This paper proposes an optimization model based on minimizing trade costs. On one hand, this model can satisfy each country's demand for crude oil. On the other hand, it can minimize the cost of crude oil trade. By applying complex network theory and metaheuristic algorithm, the optimal distribution configuration of crude oil between supply and demand countries is obtained, which provides new ideas and perspectives for discussing the optimization of the crude oil trading system.

The paper is organized as follows. Section 2 describes a simplified crude oil trade bipartite network model, the optimization model, and the simulated annealing method. Section 3 empirically analyzes the scenario of crude oil interactions between exporters and importers to obtain a reasonable crude oil trade structure. Section 4 discusses the findings and presents conclusions.

\section{Models and Methodology}

2.1. Crude Oil Trade Bipartite Network Model. The global crude oil trade can be divided into supply side and demand side so that the global crude oil trade network can be regarded as a bipartite network. Bipartite network is a graph, whose nodes can be divided into two disjoint and independent sets such that every edge connects a node in one set to one in another set [21]. Bipartite networks are widely used in various fields [22-27].

For each country $k$, net imports $M_{k}$ (Unit: kg) are defined as

$$
M_{k}=M_{\mathrm{kI}}-M_{\mathrm{kE}}
$$

where $M_{\mathrm{kI}}$ and $M_{\mathrm{kE}}$ are the import volume and export volume of country $k$, respectively. In particular, if $M_{k}<0$, the country $k$ is a net exporter, and if $M_{k}>0$, the country $k$ is a net importer. And if $M_{k}=0$, the node $k$ is neither a net importer nor a net exporter.

Figure 1 shows an example of crude oil trade bipartite network model. According to equation (1), the trading countries are divided into two sets: one is net exporters, the other one is net importers, and the links reflect the crude oil flow. The weight of the link reflects the volume of crude oil, $x_{i j}\left(x_{i j} \geq 0, i=1,2, \ldots, n j=1,2, \ldots, m\right)$, flowing through a directed link connecting from a net exporter $i$ to a net importer $j$. Therefore, for $i$ and $j$, we have the following balance equations:

$$
\begin{aligned}
& M_{i}=-\sum_{j=1}^{m} x_{i j}, \\
& M_{j}=\sum_{i=1}^{n} x_{i j},
\end{aligned}
$$

where $0 \leq x_{i j} \leq \min \left\{-M_{i}, M_{j}\right\}$.

The degree $k_{i}$ of country $i$ is defined as the number of countries that trade with $i$. Nodes have two different degrees, the in-degree $k^{\text {in }}$, which is the number of incoming edges, and the out-degree $k^{\text {out }}$, which is the number of outgoing edges. The degree distribution is defined as

$$
P(k)=\frac{N_{k}}{N}
$$

where $N_{k}$ is the number of nodes (countries) with degree $k$.

2.2. Optimization Model. A stable crude oil market requires to be able to design a model of the optimal trade network structure based on the trade demand and the trade relationship of the net importing countries and the net exporting country for reducing the trade costs. Therefore, the problem of reducing the trade costs in crude oil trade is transformed into the topology optimization problem of the bipartite network. In other words, the purpose of the optimization model is to find the optimal configuration for the crude oil trade bipartite network.

Combined with the basic knowledge of economics and gravity model theory in international trade [28, 29], according to the characteristics of the actual crude oil trade, 


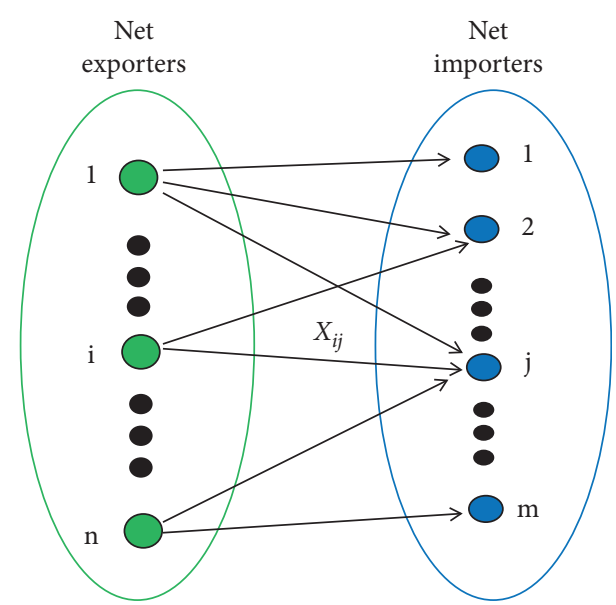

Figure 1: An example of crude oil trade bipartite network model.

it is deduced that the crude oil trade costs are proportional to trade volume and geographical distance. Therefore, we construct the equation of trade cost:

$$
C=\sum_{i, j} d_{i j} x_{i j}, \quad i=1,2, \ldots, n ; j=1,2, \ldots, m,
$$

where $d_{i j}$ is the geographical distance between net exporting country $i$ and net importing country $j$. In equation (5), the unknown variable $x_{i j}$ represents the amount of crude oil flowing from $i$ to $j$.

In order to determine the optimal configuration of the crude oil trade system, equation (5) is formulated as an optimization model, where the objective function is defined as

$$
\min C=\sum_{i, j} d_{i j} x_{i j}, \quad i=1,2, \ldots, n ; j=1,2, \ldots, m .
$$

The constraints of the problem are equations (2) and (3). The feasible solution of the optimization model can help identify which edges are needed to achieve an optimal crude oil trade structure.

2.3. Minimum Spanning Tree. The minimum spanning tree is also called the minimum weight spanning tree. It is a subset that contains all the vertices in the graph and links all the vertices, and the total of these edge weights is minimum in the weighted undirected graph. In this paper, we use Kruskal's algorithm for the minimum spanning tree [30, 31]. The process of the algorithm is as follows:

(i) Step 1. View each node in the graph as an isolated branch, and sort the edges in descending order by the weights.

(ii) Step 2. Traverse the graph once, find the edge with the maximum weight, and ensure that this edge does not loop with the edges that have been added to the minimum spanning tree collection. Add this edge to the minimum spanning tree collection if all conditions are met. Otherwise, continue to traverse the graph to find the next edge with the maximum weight.

(iii) Step 3. Recursively repeat step 1 , until $n-1$ edges are found (if the graph has $n$ nodes, the minimum spanning tree should have $n-1$ edges). Then, the algorithm terminates, and the minimum spanning tree of the graph is obtained.

2.4. Simulated Annealing Method. Simulated Annealing is a probabilistic technique for approximating the global optimum of a given function. Specifically, it is a metaheuristic to approximate global optimization in a large search space for an optimization problem [32]. Simulated Annealing can be used to find an approximation of a global minimum for a function with a large number of variables [33-35]. Simulated annealing algorithm flow chart is shown in Figure 2 $[36,37]$.

We used the sensitivity analysis method to analyze the parameters of the optimization algorithm for solving the crude oil supply and demand network design problem. First, when the maximum number of iterations, the cooling rate, and the termination temperature are fixed, and the initial temperature $T_{0}$ is increased from 40 to 500 , the solution result and solving time are shown in Figures 3(a) and $3(b)$. When the initial temperature, cooling rate and termination temperature are fixed, and the maximum number of iterations $t_{\max }$ is increased from 600 to 1500 , the solution result and solving time are as shown in Figures 3(c) and 3(d). The number of iterations of the simulated annealing algorithm needs to be large enough to ensure that the algorithm reaches equilibrium. However, if it is too large, it will greatly increase the time spent. Considering the above results and solving time, the selected parameters $T_{0}=100, t_{\max }=1000, c=0.999$ are appropriate, the number of solutions reaches $4.6 \times 10^{6}$ times, and the termination temperature is $T_{k}<1$.

How to generate the solution is an important part of the simulated annealing method. Here, the way for generating the solution is proposed in the following steps:

(i) Step 1. Randomly select a country in the collection of net exporting countries, denoted as $E_{1}$.

(ii) Step 2. Compare the geographical distance between all net importing countries and $E_{1}$, then choose the net importing country $\left(I_{4}\right)$, which has the shortest distance to trade in order from $E_{1}$.

(iii) Step 3. Determine whether $E_{1}$ exports all crude oil to $I_{4}$. If $E_{1}$ exports all of its crude oil but $I_{4}$ still has 


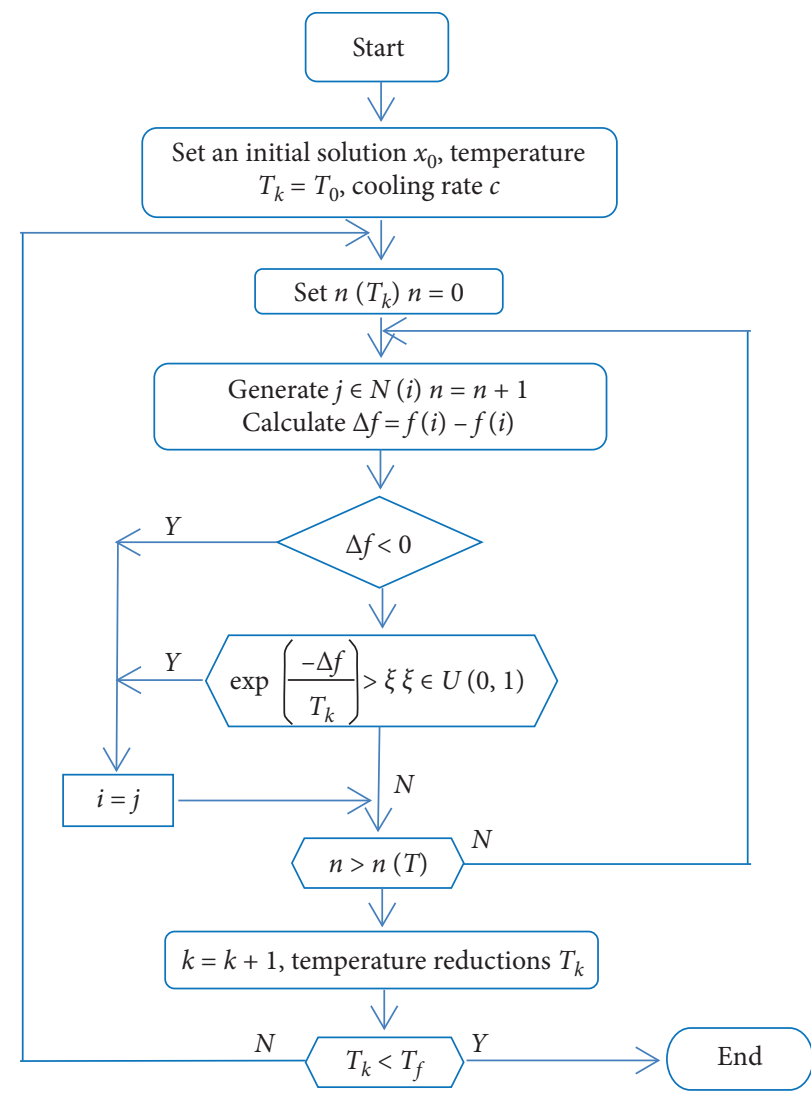

FIGURE 2: Simulated annealing algorithm flow chart.

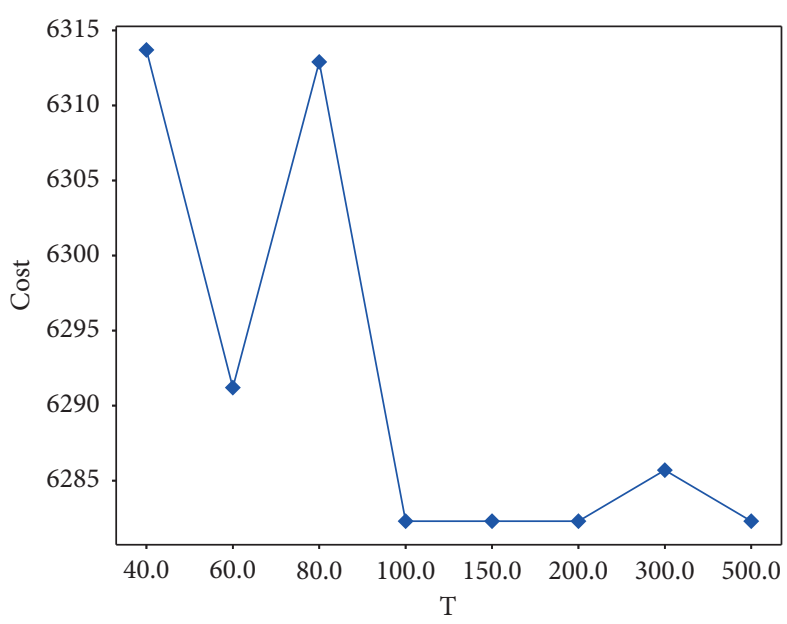

(a)

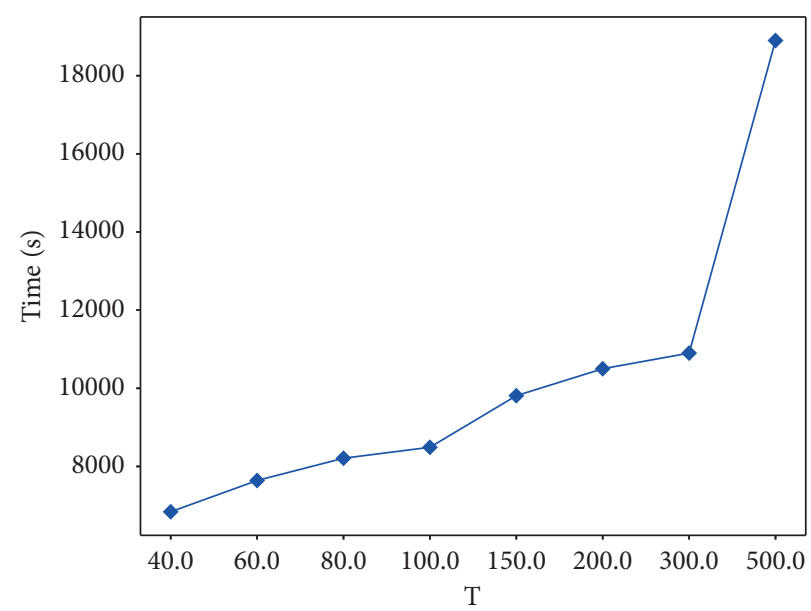

(b)

FIgURE 3: Continued. 


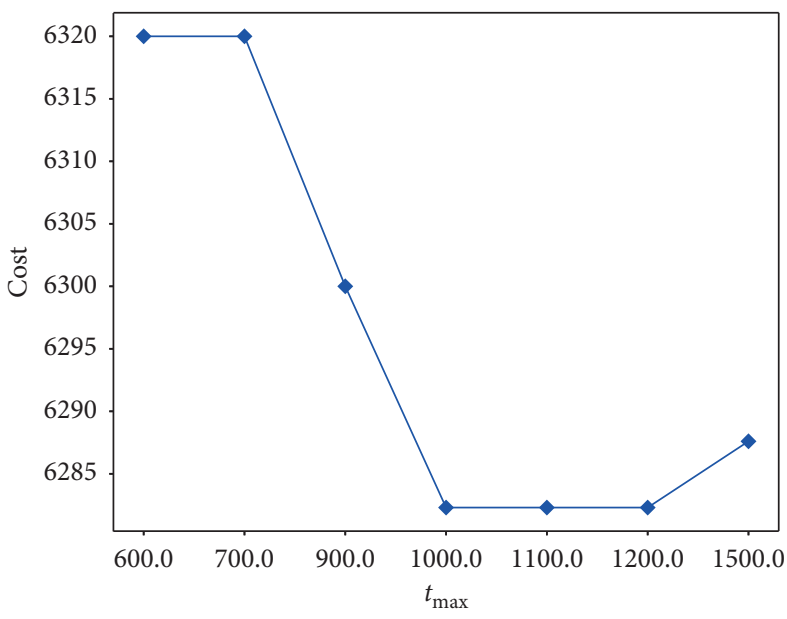

(c)

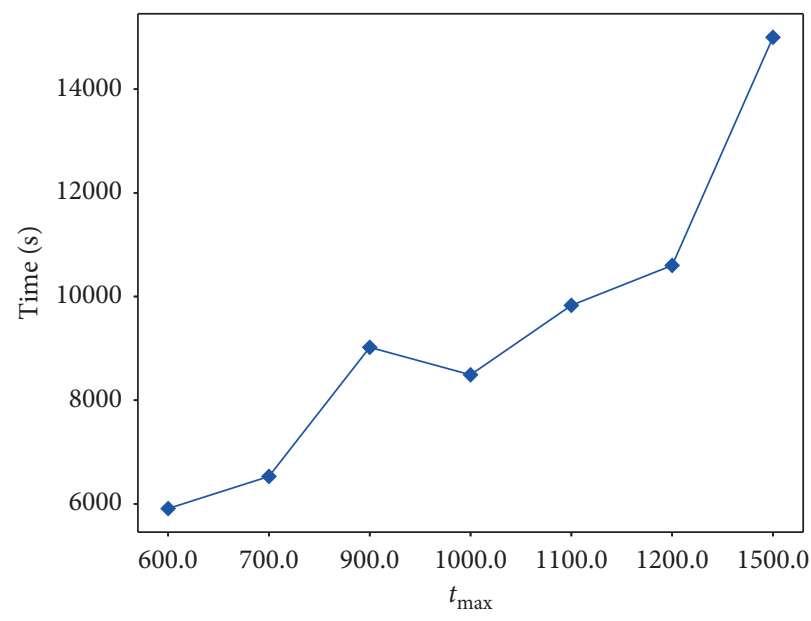

(d)

Figure 3: Sensitivity with respect to $T_{0}\left(t_{\max }=1000, c=0.999\right)$ and $t_{\max }\left(T_{0}=100, c=0.999\right)$. (a) Cost vs. $T_{0}$. (b) Solving time vs. $T_{0}$. (c) Cost vs. $t_{\max }$ (d) Solving time vs. $t_{\max }$.

demand, remove $E_{1}$ and retain $I_{4}$; if $I_{4}$ obtains the required crude oil and $E_{1}$ has remainder, remove $I_{4}$ and retain $E_{1}$.

By repeating the above steps, combined with the Simulated Annealing method, any possible trade process can be simulated. Thus, the solution obtained must be optimal, and the resulting structure is the optimal configuration.

\section{Empirical Analysis}

3.1. Data. We choose the global crude oil trade volume (unit: billion tons) as the sample data. The data cover the period from 2010 to 2016 . All the data are obtained from the website of the United Nations Commodity Trade Database [38]. The used code is HS 270900: crude petroleum oils. Geographic distance data (unit: kilometers) is obtained from the website of the CEPII [39]. Table 1 shows the numbers of global crude oil trading countries from 2010 to 2016.

3.2. Topological Structure Analysis. This section represents the application of the model and method described in Section 2 to actual crude oil trade. The optimization model has been run for the global crude oil trade during 2010 and 2016 to yield the optimal bipartite network structure.

Table 2 compares the costs of preoptimized and optimized crude oil trade. The results show that the cost of the crude oil trade after optimization is greatly reduced. This confirms the effectiveness of our proposed optimization method.

We take the optimization results of 2010 and 2016 as examples, and the optimized crude oil trade structure for 2010 and 2016 is shown in Figure 4. The dots in Figure 4 represent the countries trading in crude oil. The size and color of the dots reflect the size of the country's in-degree or out-degree. For example, if a node with in-degree (outdegree) $=2$, in Figure 4, it is represented by a circle with the second smallest radius, and the color is green. The links with arrows indicate the flow of crude oil.
Figures 5 and 6 compare the in-degree, out-degree, and degree distributions of the global crude oil trading network before and after optimization. We find that all the figures reveal "long tail" effect, which is a characteristic of scale-free networks, and the degree distribution follows power-law distribution. It indicates that there are a small number of "hub" trading countries with a high degree of nodes and a large number of "peripheral" trading countries with a low degree of nodes. These high-degree nodes play an important supporting role in the network. In other words, removing these nodes will cause devastating damage to the system. In the trade network, although the number of nodes in the network has changed, the optimal selection mechanism in the scale-free network cannot be fully reflected, which weakens this feature to a certain extent [40].

3.3. The Minimum Spanning Tree Analysis. The minimum spanning tree of the global crude oil trading network reflects the central relationship between the trading countries.

Figures 7 and 8 show the minimum spanning tree for the preoptimized and optimized crude oil trade network. In the minimum spanning tree, the greater the degree of the node (trading country), the stronger its influence in the global crude oil trade. Tables 3 and 4, respectively, show the variance of the top 10 countries with node degrees in the minimum spanning trees of crude oil trade before and after optimization during 2010 and 2016. The countries for Tables 3 and 4 in our selected sample are shown in Table 5. We find that, for the preoptimized crude oil trade, among the top 10 countries, there are both major net exporters (light gray area of the table) and major net importers (white area of the table). And their numbers are almost the same. However, in terms of the optimized crude oil trade, most of the top 10 countries are major net exporters (light gray area of the table). It indicates that, in the crude oil trade before optimization, the major net importers and the major net exporters have an equally important influence. In contrast, in 
TABle 1: Numbers of crude oil trading countries from 2010 to 2016.

\begin{tabular}{lccccccc}
\hline & 2010 & 2011 & 2012 & 2013 & 2014 & 2015 & 2016 \\
\hline Net exporters & 47 & 48 & 51 & 48 & 52 & 44 & 43 \\
Net importers & 100 & 103 & 98 & 99 & 101 & 99 \\
Total & 147 & 151 & 149 & 147 & 153 & 143 \\
\hline
\end{tabular}

TABLE 2: The trade costs comparison of preoptimized and optimized crude oil trade.

\begin{tabular}{lccccccc}
\hline Trade cost $\left(\times 10^{3}\right)$ & 2010 & 2011 & 2012 & 2013 & 2014 & 2015 & 2016 \\
\hline Before optimization & 8.2538 & 12.086 & 12.445 & 8.1666 & 7.7386 & 7.8914 & 8.1218 \\
After optimization & 6.2823 & 8.5319 & 8.6179 & 6.2141 & 5.7190 & 5.7618 & 6.1643 \\
\hline
\end{tabular}

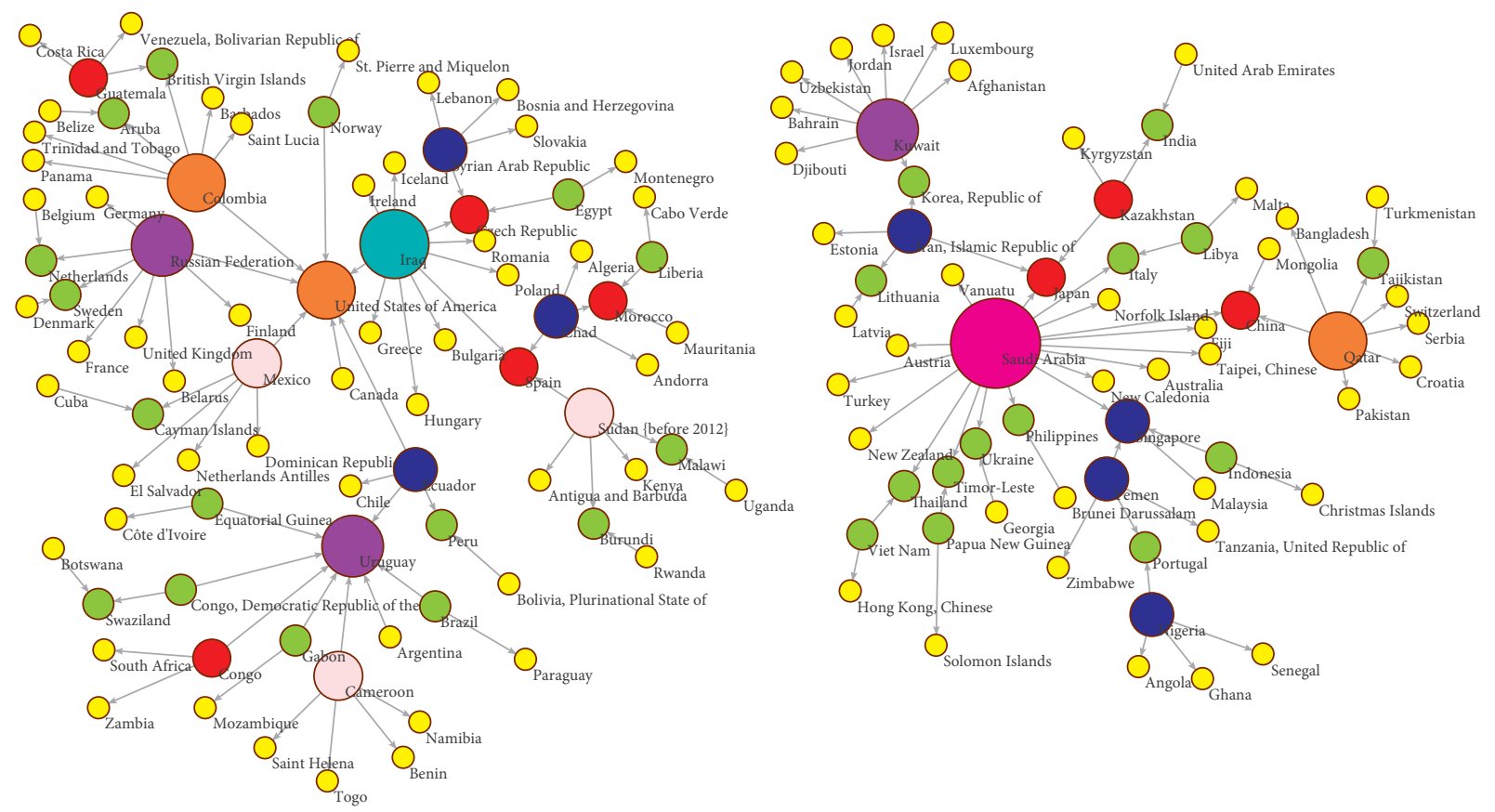

(a)

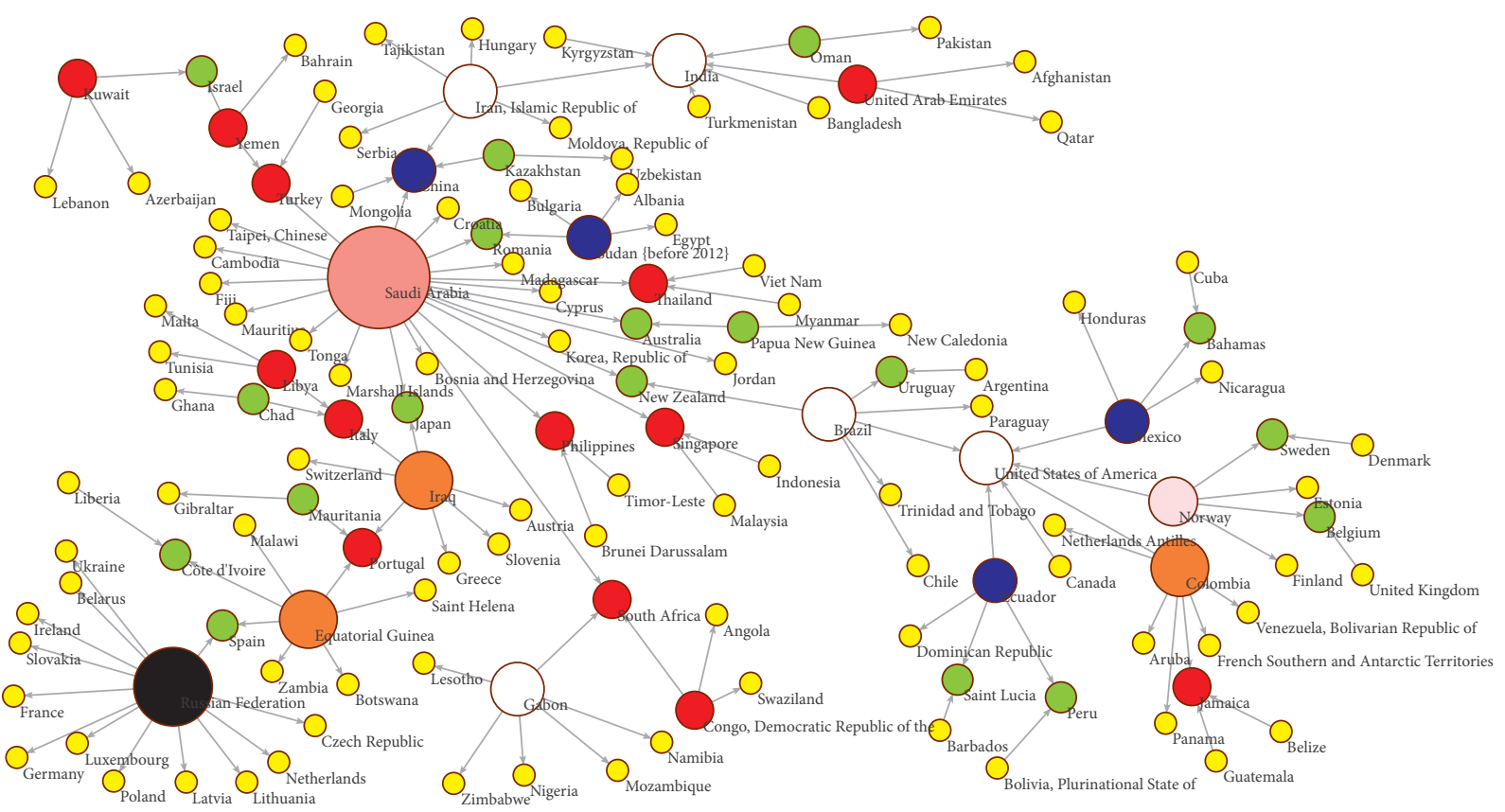

(b)

FIgURE 4: The optimal crude oil bipartite network structure: (a) 2010; (b) 2016. 

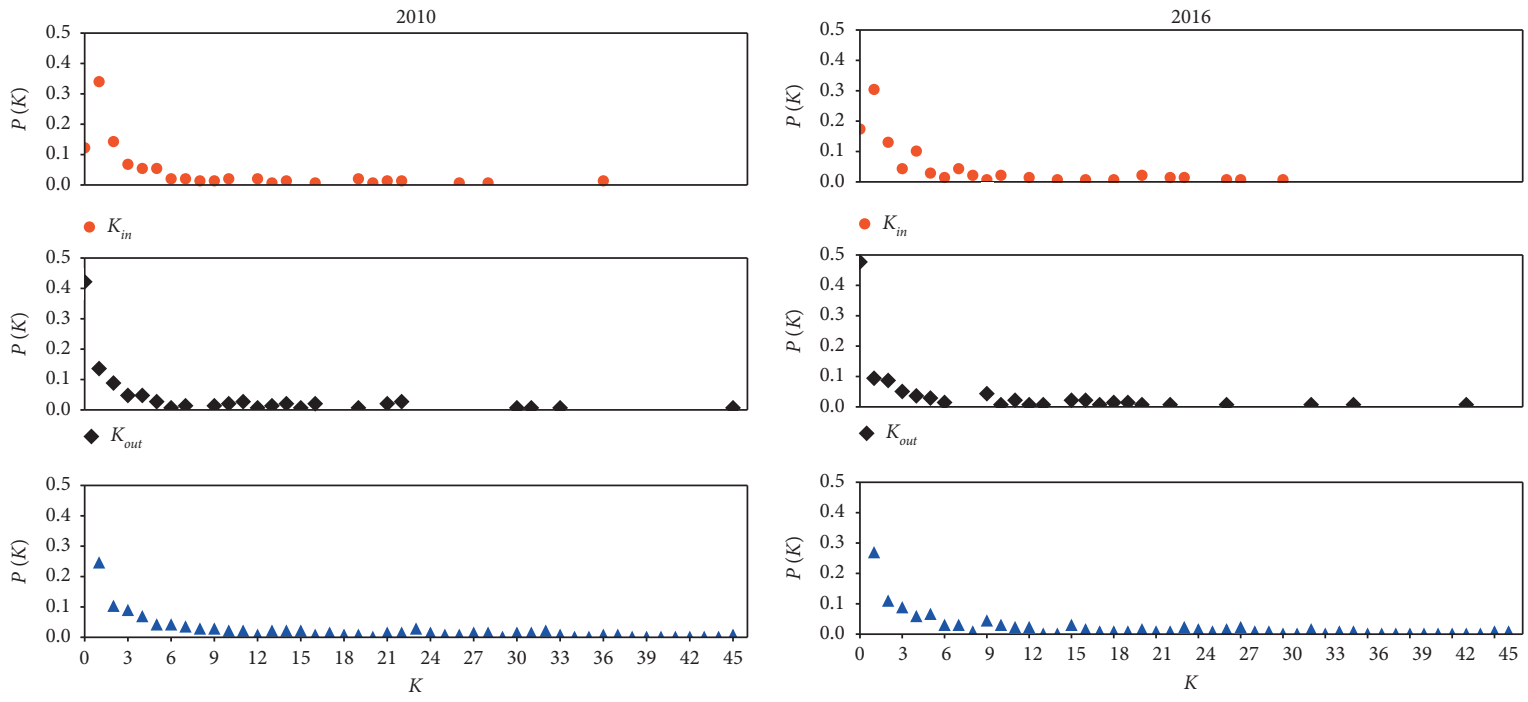

A $K$

$\Delta K$

(a)

(b)

Figure 5: The in-degree, out-degree, and degree distributions of the global crude oil trade network before optimization: (a) 2010 ; (b) 2016.
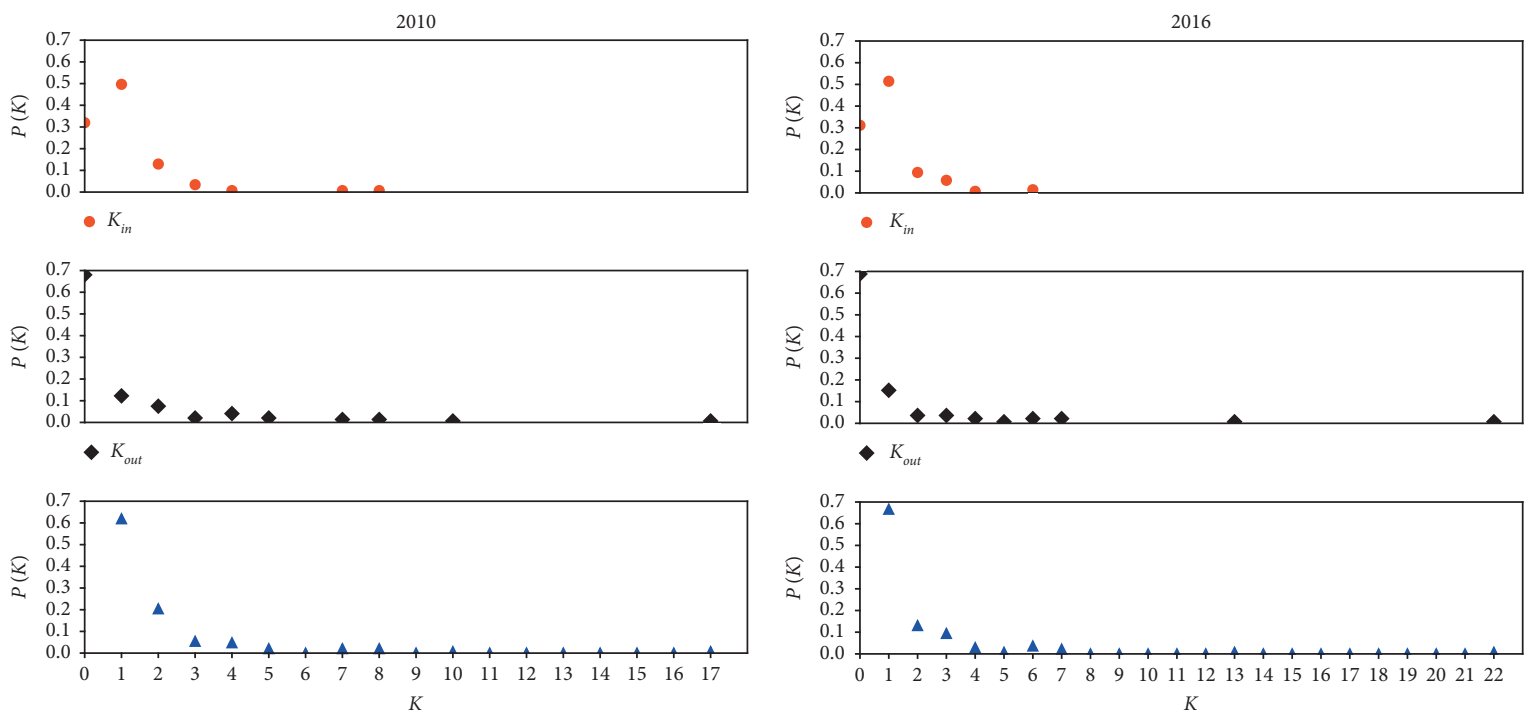

\ $K$

(b)

Figure 6: The in-degree, out-degree, and degree distributions of the global crude oil trade network after optimization: (a) 2010 ; (b) 2016. 


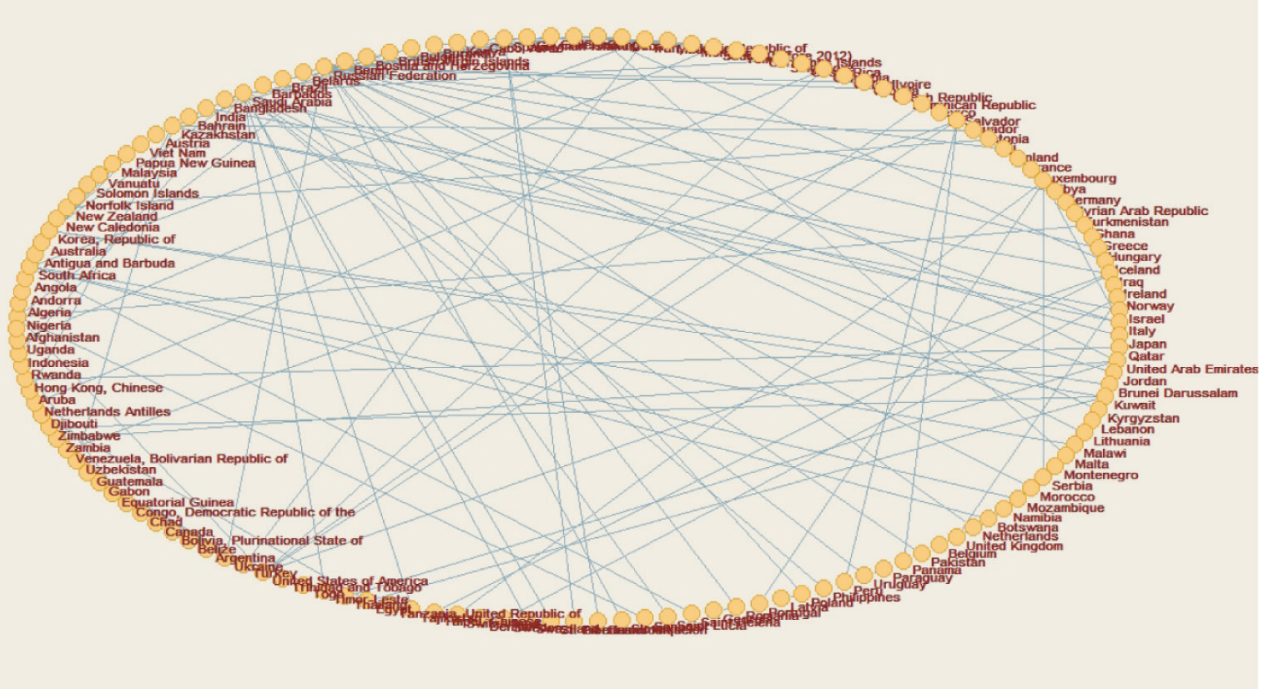

(a)

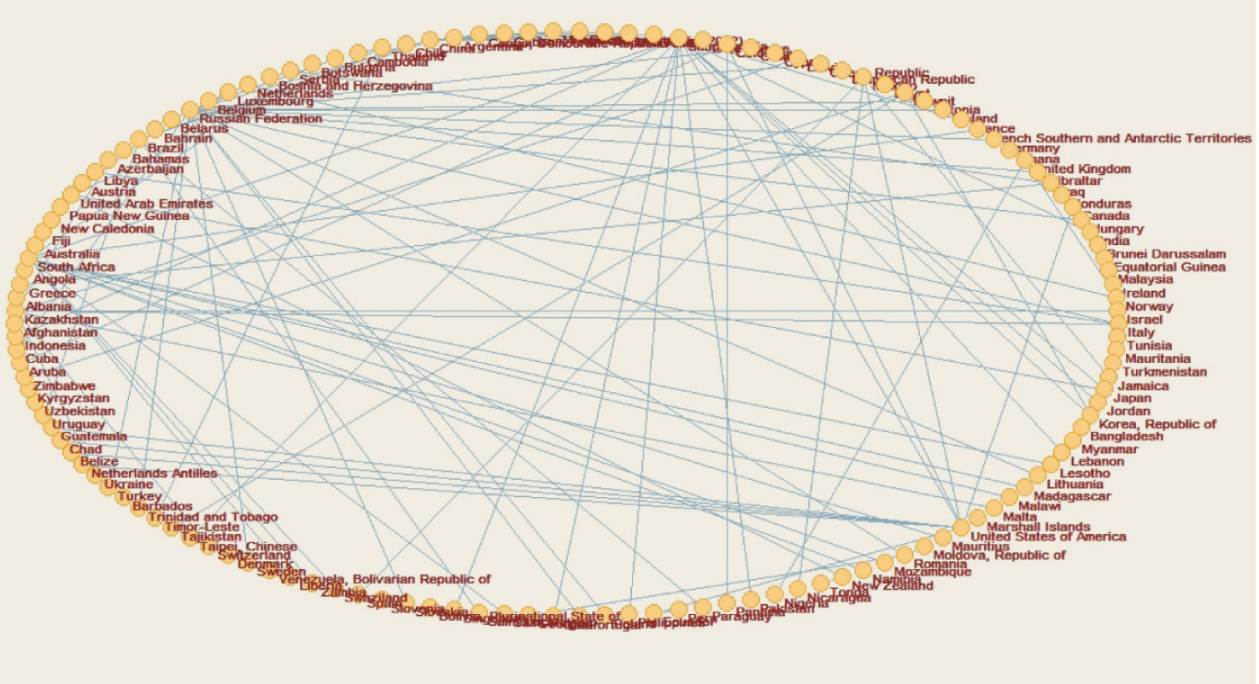

(b)

Figure 7: Minimum spanning tree of the global crude oil trading network before optimization: (a) 2010; (b) 2016.

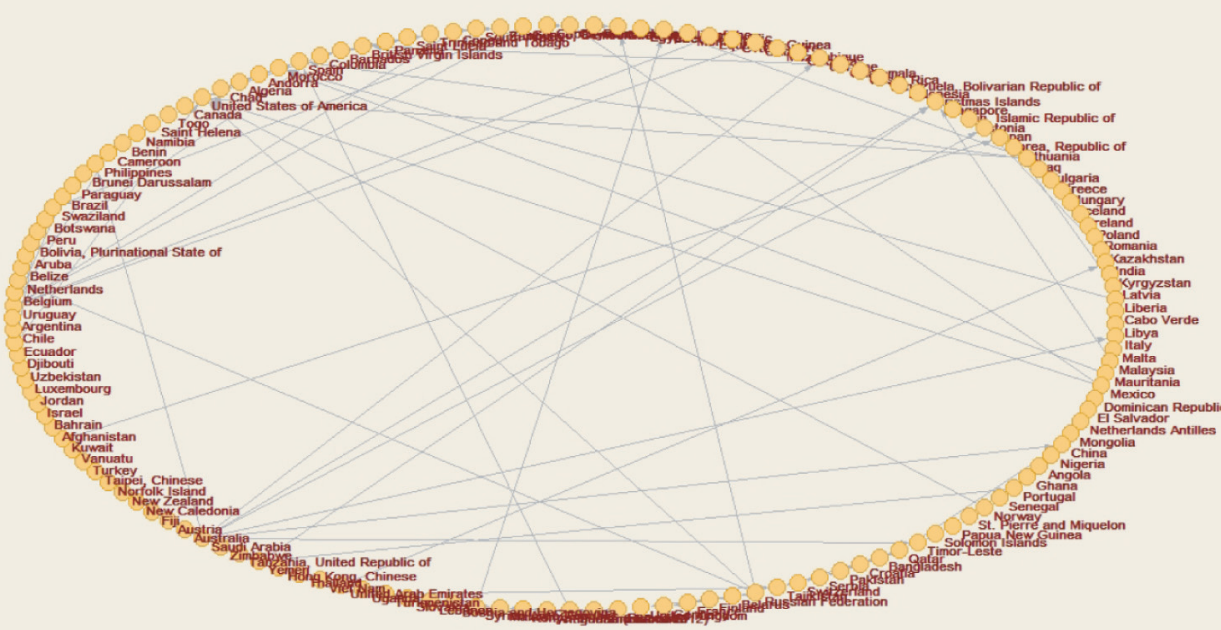

(a)

Figure 8: Continued. 


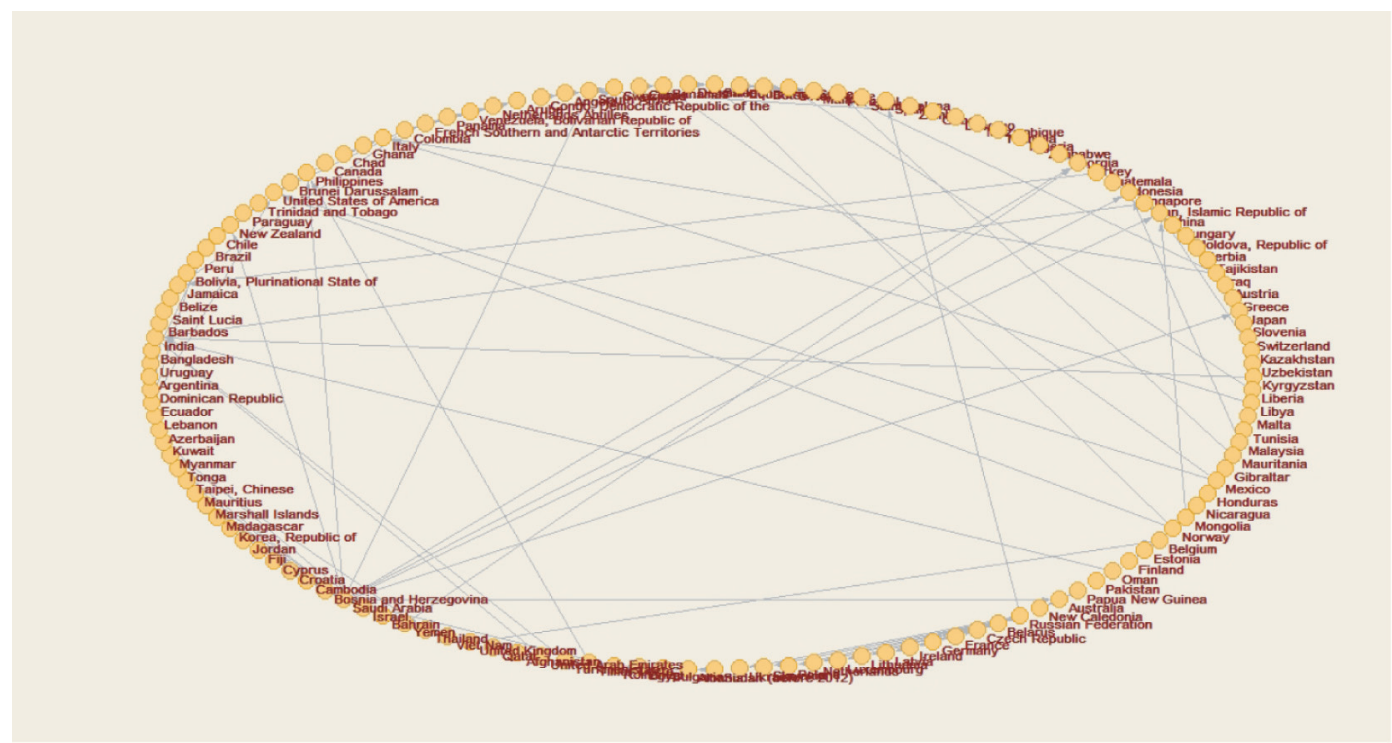

(b)

FIGURE 8: Minimum spanning tree of the global crude oil trading network after optimization: (a) 2010; (b) 2016.

TABLE 3: The variance of the top 10 countries with node degrees in minimum spanning trees of crude oil trade before optimization during 2010 and 2016. The light gray spaces represent the major crude oil exporting countries (see Table 5 for the countries in the selected sample).

\begin{tabular}{lllllcc}
\hline Top & 2010 & 2011 & 2012 & 2013 & 2014 & 2015 \\
\hline 1 & RU & RU & RU & RU & RU & RU \\
2 & SA & SA & SA & SA & SA & SA \\
3 & US & US & US & CN & CN & CN \\
4 & CN & CN & CN & KZ & US & US \\
5 & AU & KZ & CO & US & ZA & KZ \\
6 & NG & NG & KZ & AE & AU & AU \\
7 & KZ & AE & IN & ZA & KZ & ZA \\
8 & ZA & CO & AE & JP & AE & IT \\
9 & LY & BR & JP & NG & IT & CO \\
10 & BR & AU & ZA & IN & IN & BR \\
\hline
\end{tabular}

TABLE 4: The variance of the top 10 countries with node degrees in minimum spanning trees of crude oil trade after optimization during 2010 and 2016. The light gray spaces represent the major crude oil exporting countries (see Table 5 for the countries in the selected sample).

\begin{tabular}{lccccccc}
\hline Top & 2010 & 2011 & 2012 & 2013 & 2014 & 2015 \\
\hline 1 & SA & RU & IQ & SA & SA & SA \\
2 & IQ & SA & SA & RU & RU & RU \\
3 & UY & CO & MX & UY & IQ & GA \\
4 & RU & IQ & RU & EC & CO & CO \\
5 & KW & EC & ES & US & UY & UY \\
6 & US & UY & CO & GA & OM & OM \\
7 & CO & YE & IR & IQ & ZA & CO \\
8 & QA & IT & GR & QA & CD & MX \\
9 & CM & IR & UY & MA & GT & US \\
10 & MX & ES & CD & GQ & SD & EC \\
\hline
\end{tabular}


TABLe 5: Countries in the selected sample.

\begin{tabular}{lcccc}
\hline Abbreviation & & & & \\
\hline Australia & AU & India & IN & Oman \\
Brazil & BR & Iran & IR & Qatar \\
Cameroon & CM & Iraq & IQ & Russian Federation \\
China & CN & Italy & IT & Saudi Arabia \\
Colombia & CO & Japan & JP & South Africa \\
The Democratic Republic of the Congo & CD & Kazakhstan & KZ & SA \\
Ecuador & EC & Kuwait & KW & Sudan \\
Equatorial Guinea & GQ & Libya & LY & United Arab Emirates \\
Gabon & GA & Mexico & MX & United States of America \\
Greece & GR & Morocco & MA & AE \\
Guatemala & GT & Nigeria & NG & Urugua \\
\hline
\end{tabular}

the optimized crude oil trade, the major net exporting countries are at the core.

\section{Conclusions}

In this paper, based on the yearly crude oil trade volume data from 2010 to 2016 and geographic distance data, we propose an optimization methodology based on the complex network approach. This approach allows oil trading countries to be represented as nodes and oil flows as links. The optimal crude oil trade structure has been obtained by fixing the trade volume of each country and minimizing the total trade cost. The resulting feasible solution helps exploit reasonable trade relationships.

Compared with the preoptimized trade network, the proposed model can effectively reduce the trade cost. Meanwhile, we find that both the preoptimized and optimized crude oil trade networks follow power-law distribution, which means that most countries have fewer trading partners, while fewer countries have established trade relations with a large number of countries.

Additionally, in order to identify countries with significant influence, the minimum spanning tree analysis has yielded some promising results, which show that, in the crude oil trade before optimization, the major net importers and major net exporters have an equally important influence. However, in the crude oil trade after optimization, the major net exporters have the greatest influences. In other words, they are at the core.

The research results provide a fresh perspective for the optimization of the crude oil trade network structure. In addition, the methodology and findings can help policymakers formulate reasonable and effective trade strategies. Further work will focus on the impact of trade preference factor on optimizing the structure of crude oil trade, thus establishing a more realistic and comprehensive optimization model.

\section{Data Availability}

The data are available upon request.

\section{Conflicts of Interest}

The authors declare that they have no conflicts of interest.

\section{Acknowledgments}

This research was supported by grants from the National Natural Science Foundation of China (Grant nos. 61973143 and 71974080), the Major Program of National Natural Science Foundation of China (Grant no. 71690242), the National Natural Science Foundation of China (Grant no. 11731014), National Key R\&D Program of China (Grant no. 2020YFA0608601), and young backbone teachers of Jiangsu Province.

\section{References}

[1] M. Girvan and M. E. J. Newman, "Community structure in social and biological networks," Proceedings of the National Academy of Sciences, vol. 99, no. 12, pp. 7821-7826, 2002.

[2] S. Boccaletti, V. Latora, Y. Moreno, M. Chavez, and D.-U. Hwang, "Complex networks: structure and dynamics," Physics Reports, vol. 424, no. 4-5, pp. 175-308, 2006.

[3] R. Cohen and S. Havlin, Complex Networks: Structure, Robustness and Function, Cambridge University Press, Cambridge, UK, 2010.

[4] S. V. Buldyrev, R. Parshani, G. Paul, H. E. Stanley, and S. Havlin, "Catastrophic cascade of failures in interdependent networks," Nature, vol. 464, no. 7291, pp. 1025-1028, 2010.

[5] G. G. Dong, J. X. Gao, R. J. Du et al., "Robustness of network of networks under targeted attack," Physical Review E, vol. 87, no. 5, Article ID 052804, 2013.

[6] J. Gao, B. Barzel, and A.-L. Barabási, "Universal resilience patterns in complex networks," Nature, vol. 530, no. 7590, pp. 307-312, 2016.

[7] R. Q. Li, L. Dong, J. Zhang et al., "Simple spatial scaling rules behind complex cities," Nature Communications, vol. 8, no. 1, pp. 1-7, 2017.

[8] G. Dong, J. Fan, L. M. Shekhtman et al., "Resilience of networks with community structure behaves as if under an external field," Proceedings of the National Academy of Sciences, vol. 115, no. 27, pp. 6911-6915, 2018.

[9] Y. Yang, J. P. H. Poon, Y. Liu, and S. Bagchi-Sen, "Small and flat worlds: a complex network analysis of international trade in crude oil," Energy, vol. 93, pp. 534-543, 2015.

[10] X. Xi, J. Zhou, X. Gao, D. Liu, H. Zheng, and Q. Sun, “Impact of changes in crude oil trade network patterns on national economy," Energy Economics, vol. 84, Article ID 104490, 2019.

[11] C. Zhang, J. Fu, and Z. Pu, "A study of the petroleum trade network of countries along "The Belt and Road Initiative", Journal of Cleaner Production, vol. 222, pp. 593-605, 2019. 
[12] Q. Guan and H. An, "The exploration on the trade preferences of cooperation partners in four energy commodities' international trade: crude oil, coal, natural gas and photovoltaic," Applied Energy, vol. 203, pp. 154-163, 2017.

[13] R. Du, Y. Wang, G. Dong et al., "A complex network perspective on interrelations and evolution features of international oil trade, 2002-2013," Applied Energy, vol. 196, pp. 142-151, 2017.

[14] W. Zhong, H. An, L. Shen, W. Fang, X. Gao, and D. Dong, "The roles of countries in the international fossil fuel trade: an emergy and network analysis," Energy Policy, vol. 100, pp. 365-376, 2017.

[15] Q. Ji, H.-Y. Zhang, and Y. Fan, "Identification of global oil trade patterns: an empirical research based on complex network theory," Energy Conversion and Management, vol. 85, pp. 856-865, 2014.

[16] Q. Sun, X. Gao, W. Zhong, and N. Liu, "The stability of the international oil trade network from short-term and longterm perspectives," Physica A: Statistical Mechanics and Its Applications, vol. 482, pp. 345-356, 2017.

[17] H. An, W. Zhong, Y. Chen, H. Li, and X. Gao, "Features and evolution of international crude oil trade relationships: a trading-based network analysis," Energy, vol. 74, pp. 254-259, 2014.

[18] Q. Guan, H. An, X. Gao, S. Huang, and H. Li, "Estimating potential trade links in the international crude oil trade: a link prediction approach," Energy, vol. 102, pp. 406-415, 2016.

[19] R. J. Du, G. G. Dong, L. X. Tian et al., "Identifying the peak point of systemic risk in international crude oil importing trade," Energy, vol. 176, pp. 281-291, 2019.

[20] M. Wang, L. Tian, and R. Du, "Research on the interaction patterns among the global crude oil import dependency countries: a complex network approach," Applied Energy, vol. 180, pp. 779-791, 2016.

[21] https://en.wikipedia.org/wiki/Bipartite graph, accessed 3, 20, 2019.

[22] T. K. Moon, Error Correction Coding: Mathematical Methods and Algorithms, John Wiley \& Sons, Hoboken, NJ, USA, 2005.

[23] Y. Matsuo and H. Yamamoto, "Community gravity: measuring bidirectional effects by trust and rating on online social networks," in Proceedings of the 18th International Conference on World Wide Web, pp. 751-760, Madrid, Spain, April 2009.

[24] F. Ricci, L. Rokach, and B. Shapira, "Introduction to recommender systems handbook," in Recommender Systems Handbook, pp. 1-35, Springer, Boston, MA, USA, 2011.

[25] Z. Huang, D. D. Zeng, and H. Chen, "Analyzing consumerproduct graphs: empirical findings and applications in recommender systems," Management Science, vol. 53, no. 7, pp. 1146-1164, 2007.

[26] H. Gustafsson, D. J. Hancock, and J. Côté, "Describing citation structures in sport burnout literature: a citation network analysis," Psychology of Sport and Exercise, vol. 15, no. 6, pp. 620-626, 2014.

[27] S. Lattanzi and D. Sivakumar, "Affiliation networks," in Proceedings of the Forty-First Annual ACM Symposium on Theory of Computing, pp. 427-434, New York, NY, USA, May 2009.

[28] J. Tinbergen, "An analysis of world trade flows," Shaping the World Economy, vol. 3, pp. 1-117, 1962.

[29] F. Rauch, "The geometry of the distance coefficient in gravity equations in international trade," Review of International Economics, vol. 24, no. 5, pp. 1167-1177, 2016.

[30] https://en.wikipedia.org/wiki/Kruskal\%27s algorithm, accessed 3, 20, 2019. 18.
[31] J. B. Kruskal, "On the shortest spanning subtree of a graph and the traveling salesman problem," Proceedings of the American Mathematical Society, vol. 7, no. 1, p. 48, 1956.

[32] https://en.wikipedia.org/wiki/Simulated annealing, accessed 3, 20, 2019.

[33] A. Khachaturyan, S. Semenovskaya, and B. Vainstein, "Statistical-thermodynamic approach to determination of structure amplitude phases," Soviet Physics Crystallography, vol. 24, no. 5, pp. 519-524, 1979.

[34] A. Khachaturyan, S. Semenovsovskaya, and B. Vainshtein, "The thermodynamic approach to the structure analysis of crystals," Acta Crystallographica Section A, vol. 37, no. 5, pp. 742-754, 1981.

[35] C. Wang, D. Mu, F. Zhao, and J. W. Sutherland, "A parallel simulated annealing method for the vehicle routing problem with simultaneous pickup-delivery and time windows," Computers \& Industrial Engineering, vol. 83, pp. 111-122, 2015.

[36] P. Asokan, R. Saravanan, and K. Vijayakumar, "Machining parameters optimisation for turning cylindrical stock into a continuous finished profile using genetic algorithm (GA) and simulated annealing (SA)," The International Journal of Advanced Manufacturing Technology, vol. 21, no. 1, pp. 1-9, 2003.

[37] K. Bouleimen and H. Lecocq, "A new efficient simulated annealing algorithm for the resource-constrained project scheduling problem and its multiple mode version," European Journal of Operational Research, vol. 149, no. 2, pp. 268-281, 2003.

[38] http://www.trademap.org/Country SelProductCountry TS. aspx., accessed 6, 10, 2017.

[39] CEPII, http://www.cepii.fr/CEPII/en/cepii/cepii.asp/, accessed 5, 31, 2017.

[40] A.-L. Barabási and R. Albert, "Emergence of scaling in random networks," Science, vol. 286, no. 5439, pp. 509-512, 1999. 